\title{
Kenya: Multisectoral engagement increases support for adolescent reproductive health
}

Frontiers in Reproductive Health

Follow this and additional works at: https://knowledgecommons.popcouncil.org/departments_sbsr-rh

Part of the Demography, Population, and Ecology Commons, Family, Life Course, and Society Commons, International Public Health Commons, Maternal and Child Health Commons, and the Medicine and Health Commons

How does access to this work benefit you? Let us know!

\section{Recommended Citation}

"Kenya: Multisectoral engagement increases support for adolescent reproductive health," FRONTIERS OR Summary no. 65. Washington, DC: Population Council, 2007. 


\section{Kenya \\ Youth}

OR Summary 65

\section{Multisectoral Engagement Increases Support for Youth RH}

Collaboration among three key government ministries, communities, and local institutions helped to mainstream adolescent reproductive health activities in Kenya. Procedures and tools from the pilot project have been expanded throughout the pilot province, into two further provinces, and plans are in place to expand to an additional two provinces.

\section{Background}

In 1999, FRONTIERS launched the Kenya Adolescent Reproductive Health Project (KARHP). This study tested a multisectoral approach to improving young people's reproductive health knowledge and behavior at community, school and health facility levels in two pilot districts in Western Province. The intervention involved three ministries-Education, Science and Technology

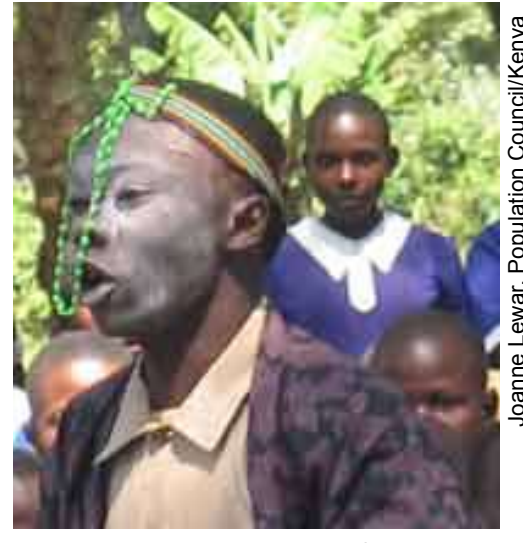

A student actor portraying AIDS at a school play, Vihiga District, Western Province, Kenya
(MOEST), Health $(\mathrm{MOH})$, and Gender, Sports, Culture and Social Services (MGSCSS) - with input from community leaders, parents, and youth. The positive findings from the study (see OR Summary no. 33) convinced the three ministries and USAID to institutionalize and scale up selected elements from the pilot project.

In 2003 FRONTIERS and PATH began providing technical assistance aimed at mainstreaming and expanding cost-effective adolescent reproductive health (ARH) strategies (peer education for in- and out-of-school youth, youth-friendly health services, community mobilization, and a standard ARH curriculum and training materials). The technical assistance included development of a cadre of core trainers at each ministry, creation of a management information system, revision of materials, and integration of ARH into work plans, policies and procedures, and budgets.

\section{Major Factors in Sustainability}

Several key undertakings contributed to the institutionalization and sustainability of the KARHP activities. These included the following:

- Multisectoral government involvement. The involvement of several ministries in planning, implementing, costing, and monitoring KARHP pilot activities enhanced the ministries' commitment and attention to ARH.

- An inter-ministerial coordination group was set up to guide the KARHP activities in Western Province. These linkages facilitate networking within and among the ministries, reduce duplication of effort, and make it easier to leverage technical and financial resources.

- Incorporation of youth reproductive health into ministerial work plans. The MOH, MOEST, and MGSCSS incorporated ARH into their work plans and staff performance requirements. Districts with prior experience of implementing KARHP have been able to produce stronger workplans.

- Training. Over 2,000 officials from MOEST, $\mathrm{MOH}$, and MGSCSS received training as implementers of KARHP activities. During the scale-up phase, the number of ministry officials trained 
expanded to nearly 2,000. Over 7,000 adults (ministry officials, community and religious leaders, provincial administrators, and leaders of youth and women's groups) and 30,000 students in Western Province have received orientation on the Tuko Pamoja [We are Together] life skills curriculum.

- Regular monitoring of program activities. The monitoring system allowed the ministries to track KARHP activities as well as their own progress towards set goals. Routine participation in implementation and monitoring allowed the ministries to plan effectively, budget for program activities, and leverage support.

- Cascade training. Experience showed that training a "critical mass" of staff and representatives from about one-third of the district's primary and secondary schools built sufficient capacity for the MOEST to provide reproductive health and HIV information to the remaining schools within the province.

- Community support. At the division and community levels, social development assistants mobilized key community leaders, including chiefs, religious leaders, parents, and community members, to support the program.

\section{Utilization}

- In early 2006, the Tuko Pamoja life skills curriculum was approved for reproductive health education in all schools in Western Province. The Provincial Education Board approved and funded the expansion of the curriculum from one-third of schools (880 schools in the scale-up phase) to all schools (over 2,500) in the eight districts in the province.
- USAID and PEPFAR provided funding to expand KARHP activities throughout Western Province, and to introduce and replicate KARHP in Eastern and Nyanza provinces. Plans are underway for the USAID bilateral projects to sustain KARHP in these provinces, and for FRONTIERS to introduce KARHP into two additional provinces (Central and Nairobi).

- Parents' ability and readiness to discuss adolescent reproductive health issues increased due to KARHP community mobilization activities by the MGSCSS. Initial religious opposition to the program diminished after sensitization. Religious groups sponsoring schools (including those in the new provinces) have endorsed the program for their schools, including the Catholic Church, which has committed funds to roll out the program into 49 schools in Eastern Province.

- The three ministries have revised and endorsed the Tuko Pamoja life skills curriculum. The revised materials are also being used by international organizations, including World Vision, Population Services International, and USAID bilateral projects, in Western, Nyanza, and Eastern provinces.

\section{Policy Implications}

- Long-term lobbying and advocacy have created a supportive policy and legislative environment for ARH. FRONTIERS and PATH will continue working with the three ministries to increase visibility for ARH in national policies and guidelines. The ultimate goal is to mainstream KARHP into the three ministries country-wide.

Source: Askew, Ian, and H. Evelia. 2007. "Outline of the Kenya Adolescent Reproductive Health Project," FRONTIERS Report. Washington, DC: Population Council. See also "Kenya: Communities support adolescent reproductive health education," FRONTIERS OR Summary no. 33. Washington, DC: Population Council. Washington, DC: Population Council, 2003. Both available on our website at www. popcouncil.org/frontiers/finalreports.html or by e-mail: frontiers@pcdc.org

This publication is made possible by the generous support of the American people through the United States Agency for International Development (USAID) under the terms of Cooperative Agreement No. HRN-A-00-98-00012-00. The contents are the responsibility of the FRONTIERS Program and do not necessarily reflect the views of USAID or the United States Government. 